\title{
Analysis of bone mineral density of human bones for strength evaluation
}

\author{
S N KHAN ${ }^{1, *}$, R M WARKHEDKAR ${ }^{2}$ and A K SHYAM ${ }^{3}$ \\ ${ }^{1}$ Government College of Engineering, Aurangabad 431005, India \\ ${ }^{2}$ Government College of Engineering, Karad 415124, India \\ ${ }^{3}$ Sancheti Hospital, Pune 411005, India \\ e-mail: subim_khan@yahoo.com; raviwar.wildorchid@gmail.com; \\ drashokshyam@yahoo.co.uk
}

MS received 27 November 2013; revised 29 December 2014; accepted 27 February 2015

\begin{abstract}
The bone density (BMD) is a medical term normally referring to the amount of mineral matter per square centimetre of bones. Twenty-five patients (18 female and 7 male patients with a mean age of 71.3 years) undergoing both lumbar spine DXA scans and computed tomography imaging were evaluated to determine if $\mathrm{HU}$ correlates with BMD and T-scores. BMD is used in clinical medicine as an indirect indicator of osteoporosis and fracture risk. This medical bone density is not the true physical "density" of the bone, which would be computed as mass per volume. Dual-energy X-ray absorptiometry (DXA, previously DEXA), a means of measuring BMD, is the most widely used and most thoroughly studied bone density measurement technologies. Different types of bone strength are required for various applications, but this strength calculation requires different machines for each strength property or it is done by different software like X-ray, CT scan, DEXA and BIA. The paper includes the design of an experimental setup which performs different types of test like tension, compression, three point bending, four point bending and torsion. The modified correlation between BMD and HU for various strength calculations is found out and validated with the experimental results.
\end{abstract}

Keywords. Bone mineral density; BIA; DEXA; strength; testing.

\section{Introduction}

The femur or thigh bone is the most proximal (closest to the body) bone of the leg in vertebrates capable of walking or jumping. In human anatomy, the femur is the longest and largest bone. The average adult male femur is $48 \mathrm{~cm}$ (18.9 in) in length and $2.34 \mathrm{~cm}(0.92 \mathrm{in})$ in diameter and can

*For correspondence 
support up to 2 times the weight of an adult. It forms part of the hip joint (at the acetabulum) and part of the knee joint, which is located above. There are four eminences, or protuberances, in the human femur: the head, the greater trochanter, the lesser trochanter, and the lower extremity. They appear at various times from just before birth to about age 14 (Cristofolini et al 2006).

BMD is defined as means value expressed in Hounsfield units of each pixel. Bone material presents a complex behaviour involving heterogeneous and anisotropic mechanical properties. Moreover, bone is a living tissue; therefore, its microstructure and mechanical properties evolve with time in a process called remodelling. This phenomenon has been studied from a long time and there are many numerical models that have been formulated in the sense to predict the density distribution in various bones, mainly in the femur. A femur, tibia and mandible (all human) were scanned and the image stored in a DICOM format. DICOM images are imported in MIMICS software and different properties like BMD with Hounsfield units (HU) for 50 different materials were assigned to relate the bone mass density (Cristofolini et al 2006; Cesar Libanati et al 2009). Correlations between BMD, HU and mechanical strength properties were studied and correlation is formulated for the same (Rho et al 1995).

\subsection{Aims and objectives}

The correlation between BMD, HU and various mechanical strength properties is evaluated for cortical and cancellous bones from various body locations in various directions. The good correlations were found to exit for cancellous bone and poor for cortical bone. The aim of the present study includes

- To evaluate more accurate correlation for cortical and cancellous bones of femur.

- To statically analyse various methods to find BMD and related material properties.

- To develop online methodology to estimate BMD and related material properties.

- To find more accurate correlation for BMD, BMC, HU, E. P

- To design experimental setup to find out various mechanical properties on single machine.

\subsection{Biomechanics of bone}

Strength and stiffness are typically used to define the "health" of a bone. The slope of the curve is called as Young's modulus (E), whereas height of the curve represents the ultimate strength. The yield point represents a transition, above which strains begin to cause permanent damage to the bone structure. Post-yield strain is inversely proportional to the brittleness of the bone (Hanumantharaju \& Shivanand 2010).

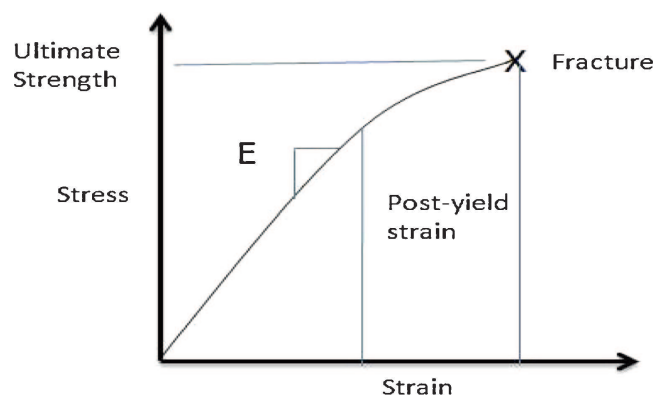

Graph 1. Stress-Strain Diagram for bone. 
Bone mineral density (BMD) is highly correlated with strength and stiffness, but there is an inverse relationship between bone stiffness (Young's modulus) and ultimate strain, shown in graph 1.

Bone samples are prepared from cortical and cancellous bones from proximal femur body parts. Three cadaver bone samples are prepared (two cancellous and one cortical bone) derived from proximal femur. These were tested on three-point hydraulic experimental setup. The observation tables for the same are as follows.

Table 1. The values of elongation, ultimate load, breaking load for various specimens.

\begin{tabular}{lccccccc}
\hline $\begin{array}{l}\text { Sr. } \\
\text { no }\end{array}$ & Specimen & $\begin{array}{c}\text { Elongation } \\
(\mathrm{mm})\end{array}$ & $\begin{array}{c}\text { Ultimate } \\
\text { load }(\mathrm{kN})\end{array}$ & $\begin{array}{c}\text { Breaking } \\
\text { load }(\mathrm{kN})\end{array}$ & $\begin{array}{c}\text { Elongation } \\
(\mathrm{mm})\end{array}$ & Strain & $\begin{array}{c}\text { UTS } \\
(\mathrm{N} / \mathrm{mm} 2)\end{array}$ \\
\hline 1 & Sample-1 & 27.03 & 68.1 & 43.89 & 27.03 & 0.54 & 867.18 \\
2 & Sample-2 & 29.38 & 68.35 & 42.69 & 29.38 & 0.58 & 870.25 \\
3 & Sample-3 & 21.94 & 68.14 & 42.84 & 21.94 & 0.43 & 867.58 \\
\hline
\end{tabular}

The overall dimensions of the proximal femur are as follows:

Sample 1:

1. Gender: Male

2. Age: 45 years

3. Diameter: $44 \mathrm{~mm}$

4. Average diameter: $28 \mathrm{~mm}$

5. Width: $75 \mathrm{~mm}$

6. Total length: $450 \mathrm{~mm}$

Sample 2:

1. Gender: male

2. Age: 47 years

3. Diameter: $44 \mathrm{~mm}$

4. Average diameter: $29.36 \mathrm{~mm}$

5. Width: $77.5 \mathrm{~mm}$

6. Total length: $470 \mathrm{~mm}$

Sample 3:

1. Gender: Male

2. Age: 46 years

3. Diameter: $44.5 \mathrm{~mm}$

4. Average diameter: $28.5 \mathrm{~mm}$

5. Width: $76 \mathrm{~mm}$

6. Total length: $460 \mathrm{~mm}$ 


\subsection{Hydraulic experimental setup}

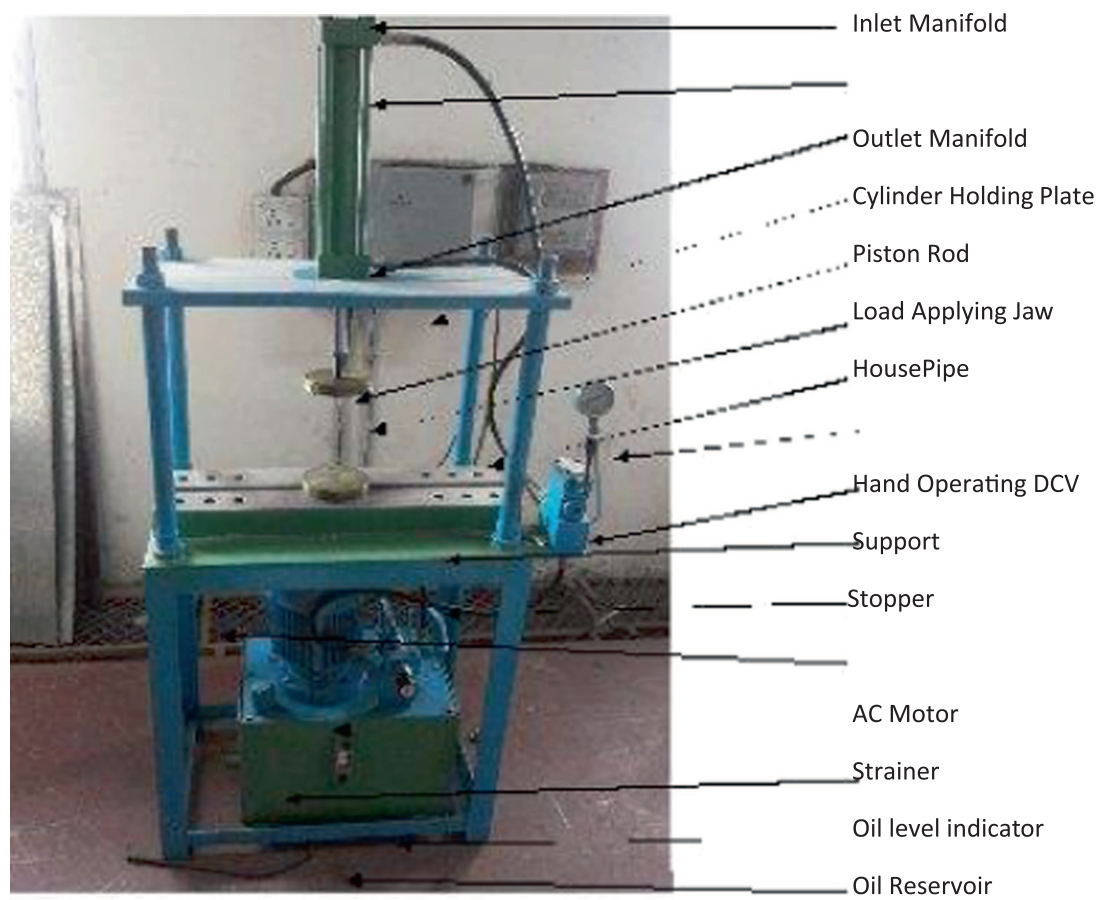

Figure 1. Hydraulic experimental setup.

\subsection{Design of hydraulic experimental setup}

Different types of bone strength are required for various applications like predicting bone fracture but these strength calculations requires different machines for each strength property or it is calculated by putting scanned data from X-ray, CT scan, DEXA, BIA etc. in existing correlations. A hydraulic experimental setup is designed and fabricated to perform different types of test like tension, compression, 3-point bending, 2-point bending and torsion. This setup is easy to operate and easy to handle maximum forces. Main advantage of this setup is its low cost and its ability to perform different tests on single setup. This experimental setup is useful in cadaveric bone study for research purpose.

This setup works on the principle of hydraulic circuit. Working of this setup is very easy, as it consist of reservoir, gear pump, double acting cylinder, pressure relief valve, direction control valve, suction strainer, check valve, oil lever indicator, pressure gauge etc. Reservoir is provided for storage of fuel. When motor starts, Gear pump sucks the fuel from reservoir and passes to direction control valve (5/3 manually operated spring return DCV) through suction strainer and check valve. DCV has a maximum pressure of 210 bars.

DCV is operated manually by changing the lever. When DCV is in position 01 , the oil is passed to double acting cylinder to the upward port and piston which is connected to the holder moves down during the forward stroke. The component or bone which is to be tested is placed on the bottom fixture and fixture is mounted on base plate. The load is applied on the bone. 


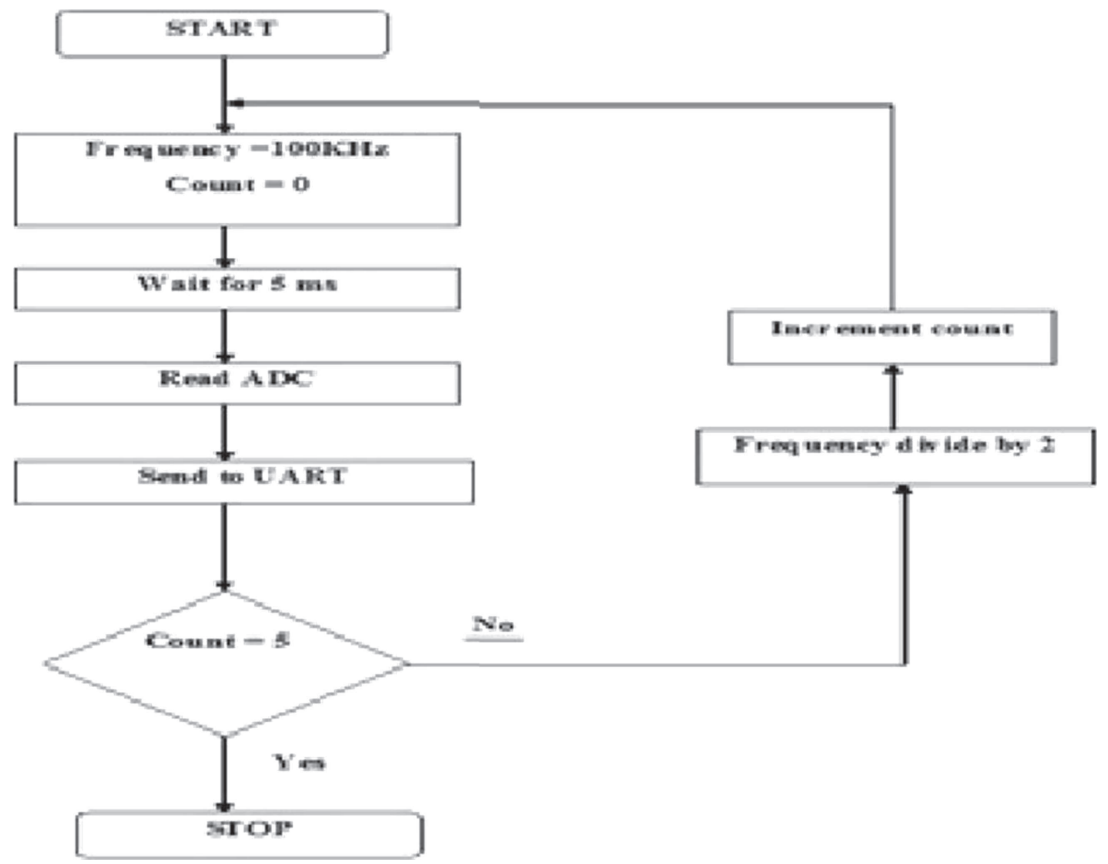

Figure 2. Stress-Strain diagram for bone. Flowchart of program BIA.

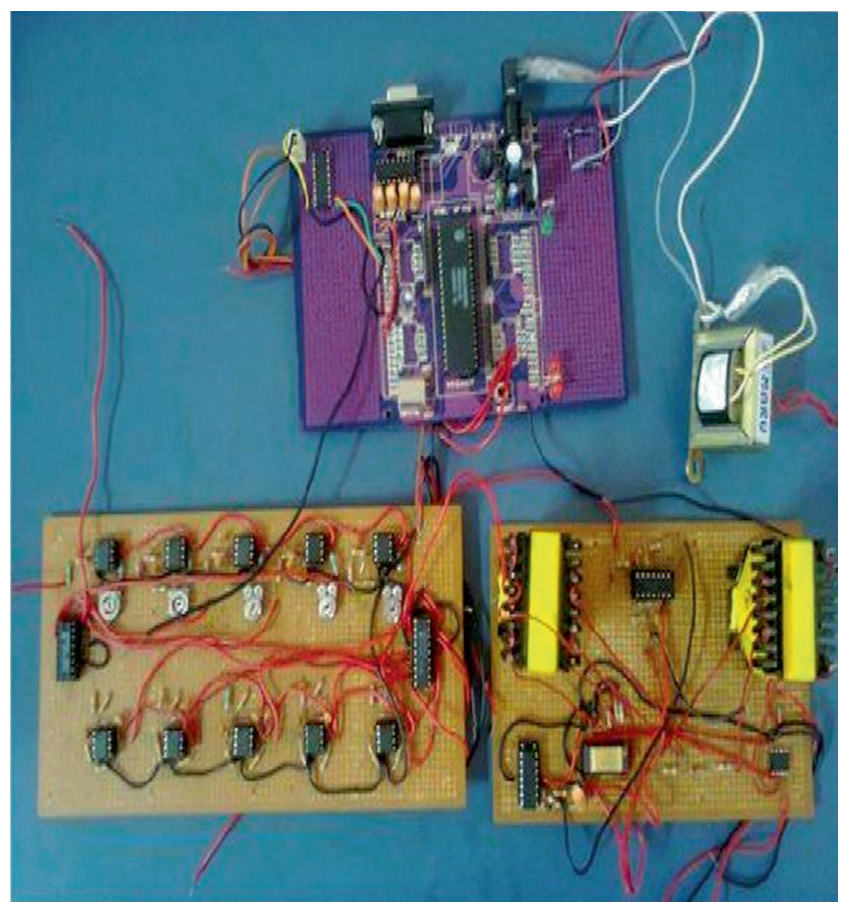

Figure 3. Actual implemented circuit of BIA. 
When DCV is in position 03, the oil from DCV is passed to bottom port of the double acting cylinder and piston moves up during the return stroke. Pressure gauge is provided to take up reading when bone or components breaks. From the pressure gauge readings we can find out the force applied to it. When DCV is in position 02, we can keep the position in hold-on position (Yuehuei \& Robert 2000).

Z-score

Z-score is the number of standard deviations away from the average value of the reference group. A person who is average has a $\mathrm{Z}$-score of 0 and is at the 50 th percentile. If the $\mathrm{Z}$-score is -0.84 then $20 \%$ of people has a lower bone density.

Calculation of $\mathrm{Z}$ score-

Z-score $=($ patient's BMD - excepted BMD $) / S D$

To calculate BMD if you know the Z-score, use the same equation by just rearranging it as

$\mathrm{BMD}=$ Expected BMD $+($ Z-score $* \mathrm{SD})$

Table 2. Data table of BMD, T-score, Z-Score and BMC.

\begin{tabular}{|c|c|c|c|c|c|}
\hline $\mathbf{N}$ & BMD & Z-Score & T-Score & BMC (BIA) & BMC (DEXA) \\
\hline 1 & 1.011 & -0.8 & -1.4 & 2.35 & 2.042 \\
\hline 2 & 1.214 & 1.3 & 1.1 & 2.28 & 1.956 \\
\hline 3 & 1.052 & -1.6 & 2.1 & 2.64 & 2.237 \\
\hline 4 & 1.116 & 0.1 & 0.1 & 2.1 & 2.19 \\
\hline 5 & 0.922 & -0.8 & -2.5 & 2 & 1.703 \\
\hline 6 & 1.125 & -0.4 & 1.2 & 2.85 & 2.492 \\
\hline 7 & 0.939 & -1.2 & -2.3 & 2.27 & 1.862 \\
\hline 8 & 0.968 & -1.6 & -2 & 2.22 & 1.959 \\
\hline 9 & 1.193 & 0.6 & 0.9 & 2.41 & 2.69 \\
\hline 10 & 0.9373 & -1.9 & -1.9 & 2.5 & 2.13 \\
\hline 11 & 1.015 & -0.3 & -0.9 & 2.24 & 2.017 \\
\hline 12 & 1.019 & -0.8 & -1.3 & 2.05 & 2.016 \\
\hline 13 & 0.943 & -0.1 & -2.3 & 1.82 & 1.326 \\
\hline 14 & 1.018 & -0.1 & -1.3 & 1.85 & 1.823 \\
\hline 15 & 1.044 & -0.3 & -1 & 2.02 & 1.958 \\
\hline 16 & 1.22 & -0.1 & 1.2 & 2.66 & 2.72 \\
\hline 17 & 1.186 & 1 & 0.8 & 2.29 & 2.317 \\
\hline 18 & 1.114 & 1.6 & -0.1 & 1.9 & 2.01 \\
\hline 19 & 1.279 & 0.6 & 0.7 & 1.76 & 2.953 \\
\hline 20 & 1.199 & 0.7 & 0.9 & 1.86 & 2.478 \\
\hline 21 & 0.876 & -1.5 & -3.1 & 1.93 & 1.416 \\
\hline 22 & 1.109 & 0.5 & -0.2 & 2.09 & 2.196 \\
\hline 23 & 1.091 & 0.8 & -0.4 & 2.13 & 2.048 \\
\hline 24 & 1.161 & 2.1 & 0.4 & 1.86 & 1.882 \\
\hline 25 & 1.112 & 0.6 & -0.2 & 2.22 & 2.226 \\
\hline
\end{tabular}


T-score

On the T-score scale, 0 represents normal, healthy bone density of a 30-year-old person (the age of peak bone density). T-scores above 0 and slightly below 0 are within the normal range. It works like a temperature scale $\&$ is shown in graph 2 . A temperature of -2 is lower than a temperature of -1 . In the same way, a T-score of -2.3 shows lower bone density than a score of -1.8 (tables 1, 2, 3, 4 and 5) is shown in graphs 3 and 4.

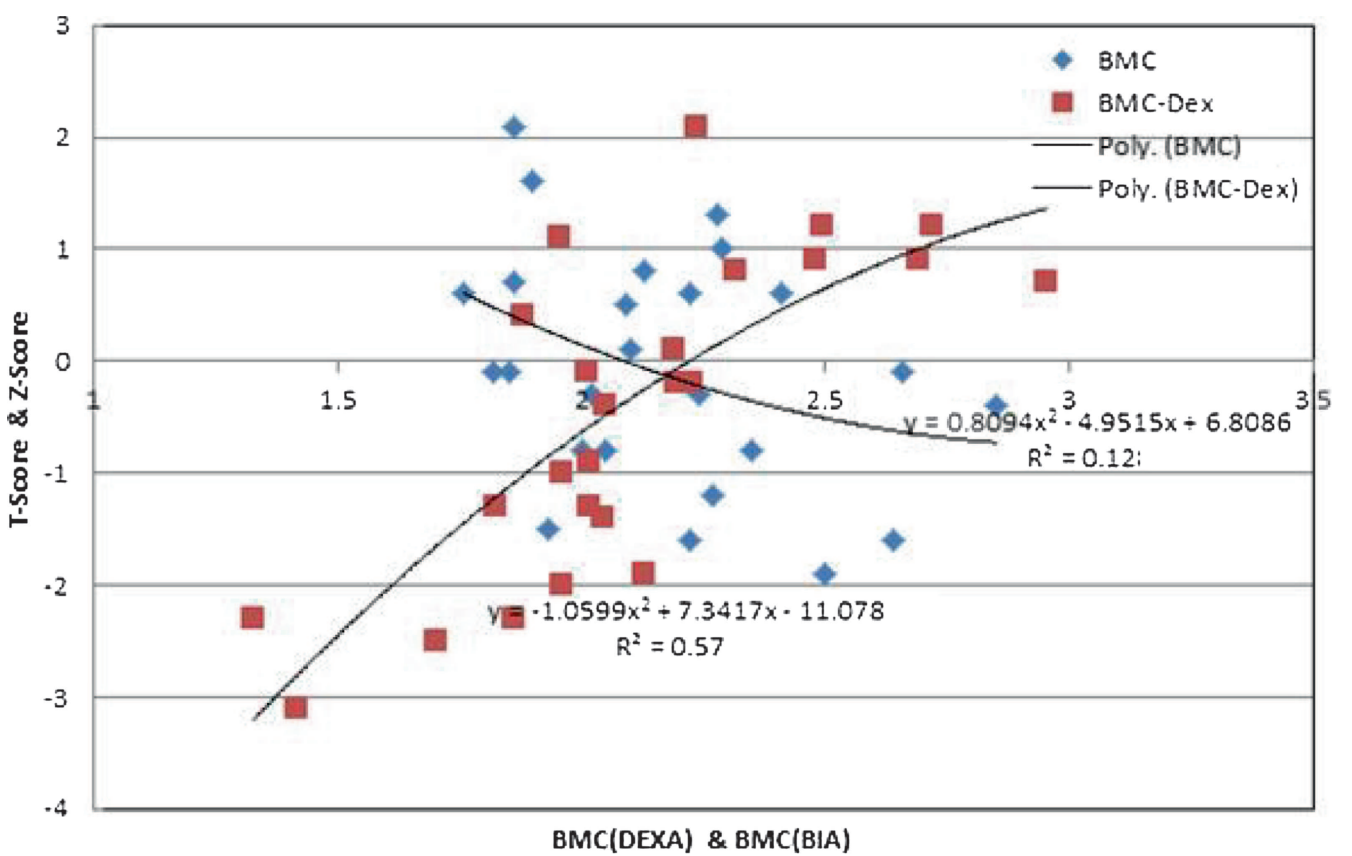

Graph 2. T- Score and Z- Score versus BMC (DEXA) and BMC (BIA).

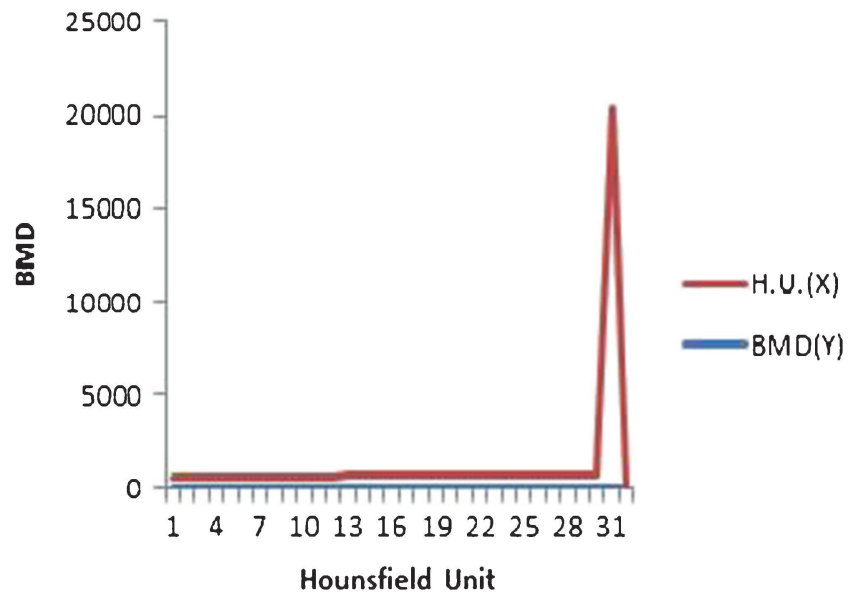

Graph 3. BMD versus Hounsfield unit. 
A T-score of -1 to 0 and above is considered normal bone density, while a T-score between -1 and -2.5 is diagnosed as osteopenia. A score of -2.5 or below is diagnosed as osteoporosis. The T-score is a radiographic diagnosis, meaning it is an X-ray diagnosis and does not imply anything about the cause of osteoporosis (Raymond et al 2008).

\section{Techniques of measuring BMD and HU:}

1. DXA (formerly known as DEXA)

Dual-energy X-ray absorptiometry (DXA, previously DEXA) is a means of measuring bone mineral density (BMD). Dual Energy X ray absorptiometry uses two phantom rods in which Xray attenuation of two phantom rods measures two different energy levels is shown in graphs 5, 6 and 7.
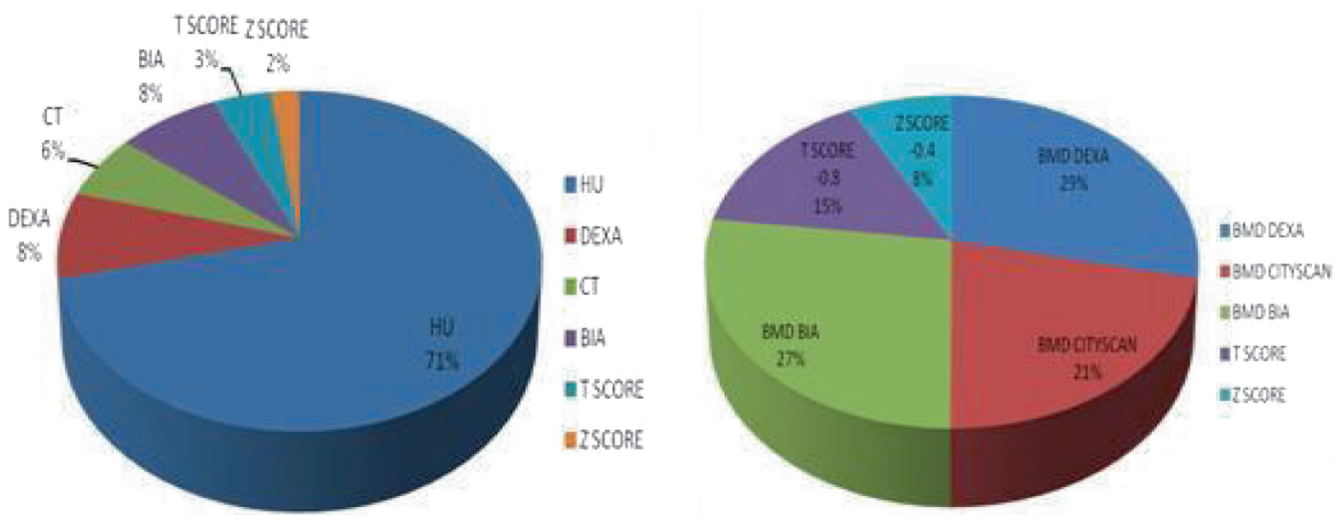

Graph 4. Pie chart analysis.

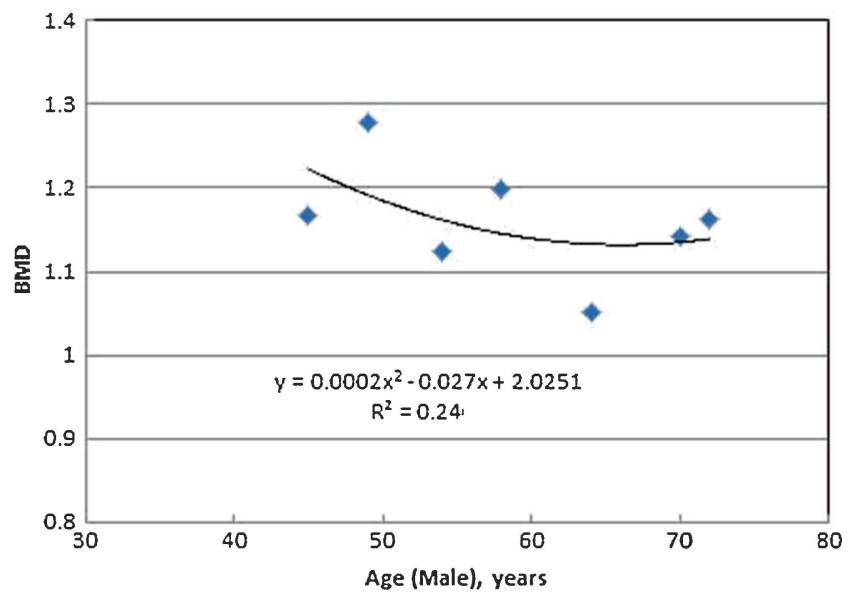

Graph 5. BMD versus age for male patients. 
2. Bio-electrical impedance analysis (BIA)

It is one of the widely used methods for estimating the body composition. BIA measurement is quick, simple and non-invasive. It is familiar in the consumer market as a simple instrument for estimating body fat. Due to its benefits and features, it is used for calculating muscle mass, fat, water, tissue and bone mineral count of a person.

Table 3. Table Error comparison for correlation between BMD and HU for different methods.

\begin{tabular}{lccc}
\hline & DEXA & CT SCAN & BIA \\
\hline R2 & 0.735248 & 0.801851 & 0.824685 \\
Standard Error of Estimate & 0.785784 & 0.588107 & 0.520334 \\
\hline
\end{tabular}

Table 4. Various age group data.

\begin{tabular}{|c|c|c|c|c|c|c|c|c|}
\hline Sr.no. & $\begin{array}{l}\text { Age } \\
\text { group }\end{array}$ & Age & Gender & Weight & $\mathrm{BMC}$ & $\begin{array}{c}\text { T- } \\
\text { Score }\end{array}$ & $\begin{array}{c}\text { Z- } \\
\text { Score }\end{array}$ & BMD \\
\hline 1 & \multirow{6}{*}{ Young } & 23 & $\mathrm{~F}$ & 48.5 & 2.196 & -0.2 & 0.5 & 1.109 \\
\hline 2 & & 24 & F & 53 & 2.016 & -1.3 & -0.8 & 1.019 \\
\hline 3 & & 34 & $\mathrm{~F}$ & 95 & 2.72 & 1.2 & -0.1 & 1.22 \\
\hline 4 & & 38 & F & 70 & 2.69 & 0.9 & 0.6 & 1.193 \\
\hline 5 & & 43 & $\mathrm{~F}$ & 49 & 1.958 & -1 & -0.3 & 1.044 \\
\hline 6 & & 45 & $\mathrm{~F}$ & 50 & 1.872 & -1.5 & -0.8 & 1.005 \\
\hline 7 & \multirow[t]{2}{*}{ Young } & 45 & M & 80 & 3.031 & -0.6 & -0.7 & 1.168 \\
\hline 8 & & 47 & $\mathrm{~F}$ & 62 & 2.317 & 0.8 & 1 & 1.186 \\
\hline 9 & \multirow[t]{8}{*}{ Adult } & 48 & $\mathrm{~F}$ & 65 & 2.19 & -0.1 & 0.1 & 1.116 \\
\hline 10 & & 49 & M & 80 & 2.953 & 0.7 & 0.6 & 1.279 \\
\hline 11 & & 49 & $\mathrm{~F}$ & 56 & 2.042 & -1.4 & -0.8 & 1.011 \\
\hline 12 & & 52 & $\mathrm{~F}$ & 65 & 1.862 & -2.3 & -1.2 & 0.939 \\
\hline 13 & & 54 & M & 61 & 2.492 & -1.2 & -0.4 & 1.125 \\
\hline 14 & & 54 & $\mathrm{~F}$ & 51 & 1.823 & -1.3 & -0.1 & 1.018 \\
\hline 15 & & 55 & $\mathrm{~F}$ & 62 & 2.226 & -0.2 & 0.6 & 1.112 \\
\hline 16 & & 55.6 & $\mathrm{~F}$ & 55 & 2.01 & -0.1 & 1.6 & 1.114 \\
\hline 17 & \multirow[t]{9}{*}{ Adult } & 58 & $\mathrm{~F}$ & 85 & 2.13 & -1.9 & -1.9 & 0.9373 \\
\hline 18 & & 58 & M & 88 & 2.478 & 0.9 & 0.7 & 1.199 \\
\hline 19 & & 58 & $\mathrm{~F}$ & 65 & 2.095 & -0.4 & 0.4 & 1.093 \\
\hline 20 & & 59 & $\mathrm{~F}$ & 80 & 1.956 & 1.1 & 1.3 & 1.214 \\
\hline 21 & & 59 & $\mathrm{~F}$ & 76 & 1.959 & -2 & -1.6 & 0.968 \\
\hline 22 & & 59 & $\mathrm{~F}$ & 48 & 1.416 & -3.1 & -1.5 & 0.876 \\
\hline 23 & & 60 & $\mathrm{~F}$ & 58 & 2.048 & -0.4 & 0.8 & 1.091 \\
\hline 24 & & 63 & $\mathrm{~F}$ & 43 & 1.326 & -2.3 & -0.1 & 0.943 \\
\hline 25 & & 64 & M & 73.1 & 2.237 & -2.1 & -1.6 & 1.052 \\
\hline 26 & \multirow[t]{2}{*}{ Age } & 64 & $\mathrm{~F}$ & 74 & 2.017 & -0.9 & -0.3 & 1.015 \\
\hline 27 & & 66 & $\mathrm{~F}$ & 56 & 1.882 & 0.4 & 2.1 & 1.161 \\
\hline 28 & \multirow[t]{4}{*}{ Match } & 66 & $\mathrm{~F}$ & 55 & 1.703 & -2.5 & -0.8 & 0.922 \\
\hline 29 & & 68 & $\mathrm{~F}$ & 88 & 2.11 & -0.6 & -0.3 & 1.086 \\
\hline 30 & & 70 & $\mathrm{~F}$ & 65 & 1.503 & -3.4 & -2 & 0.857 \\
\hline 31 & & 72 & M & 72 & 2.584 & -0.7 & 0.1 & 1.163 \\
\hline
\end{tabular}


Table 5. Correlation between BMD and HU.

\begin{tabular}{|c|c|c|c|c|c|c|c|}
\hline $\mathrm{n}$ & $\mathrm{BMD}(\mathrm{Y})$ & H.U.(X) & $X^{2}$ & $\mathrm{X}^{3}$ & $\mathrm{X}^{4}$ & $X^{*} Y$ & $\mathrm{X}^{2} * \mathrm{Y}$ \\
\hline 1 & 1.011 & 580.7 & 337212.5 & 195819293 & $1.14 \mathrm{E}+11$ & 587.0877 & 340921.8 \\
\hline 2 & 1.214 & 591.23 & 349552.9 & 206666169 & $1.22 \mathrm{E}+11$ & 717.7532 & 424357.2 \\
\hline 3 & 1.052 & 598.54 & 358250.1 & 214427034 & $1.28 \mathrm{E}+11$ & 629.6641 & 376879.1 \\
\hline 4 & 1.116 & 603.28 & 363946.8 & 219561800 & $1.32 \mathrm{E}+11$ & 673.2605 & 406164.6 \\
\hline 5 & 0.922 & 607.35 & 368874 & 224035638 & $1.36 \mathrm{E}+11$ & 559.9767 & 340101.8 \\
\hline 6 & 1.125 & 619.72 & 384052.9 & 238005250 & $1.47 \mathrm{E}+11$ & 697.185 & 432059.5 \\
\hline 7 & 0.939 & 632.81 & 400448.5 & 253407813 & $1.60 \mathrm{E}+11$ & 594.2086 & 376021.1 \\
\hline 8 & 0.968 & 640.63 & 410406.8 & 262918906 & $1.68 \mathrm{E}+11$ & 620.1298 & 397273.8 \\
\hline 9 & 1.193 & 644.89 & 415883.1 & 268198860 & $1.73 \mathrm{E}+11$ & 769.3538 & 496148.6 \\
\hline 10 & 0.9373 & 649.5 & 421850.3 & 273991737 & $1.78 \mathrm{E}+11$ & 608.7764 & 395400.2 \\
\hline 11 & 1.015 & 650.29 & 422877.1 & 274992739 & $1.79 \mathrm{E}+11$ & 660.0444 & 429220.2 \\
\hline 12 & 1.019 & 658.23 & 433266.7 & 285189162 & $1.88 \mathrm{E}+11$ & 670.7364 & 441498.8 \\
\hline 13 & 0.943 & 661.53 & 437621.9 & 289500043 & $1.92 \mathrm{E}+11$ & 623.8228 & 412677.5 \\
\hline 14 & 1.018 & 665.19 & 442477.7 & 294331765 & $1.96 \mathrm{E}+11$ & 677.1634 & 450442.3 \\
\hline 15 & 1.044 & 670.56 & 449650.7 & 301517783 & $2.02 \mathrm{E}+11$ & 700.0646 & 469435.3 \\
\hline 16 & 1.22 & 676.39 & 457503.4 & 309450746 & $2.09 \mathrm{E}+11$ & 825.1958 & 558154.2 \\
\hline 17 & 1.186 & 683.8 & 467582.4 & 319732872 & $2.19 \mathrm{E}+11$ & 810.9868 & 554552.8 \\
\hline 18 & 1.114 & 691.27 & 477854.2 & 330326282 & $2.28 \mathrm{E}+11$ & 770.0748 & 532329.6 \\
\hline 19 & 1.279 & 696.96 & 485753.2 & 338550579 & $2.36 \mathrm{E}+11$ & 891.4118 & 621278.4 \\
\hline 20 & 1.199 & 701.01 & 491415 & 344486843 & $2.41 \mathrm{E}+11$ & 840.511 & 589206.6 \\
\hline 21 & 0.876 & 713.97 & 509753.2 & 363948464 & $2.60 \mathrm{E}+11$ & 625.4377 & 446543.8 \\
\hline 22 & 1.109 & 719.25 & 517320.6 & 372082815 & $2.68 \mathrm{E}+11$ & 797.6483 & 573708.5 \\
\hline 23 & 1.091 & 727.93 & 529882.1 & 385717066 & $2.81 \mathrm{E}+11$ & 794.1716 & 578101.4 \\
\hline 24 & 1.161 & 731.57 & 535194.7 & 391532361 & $2.86 \mathrm{E}+11$ & 849.3528 & 621361 \\
\hline 25 & 1.112 & 739.85 & 547378 & 404977630 & $3.00 \mathrm{E}+11$ & 822.7132 & 608684.4 \\
\hline 26 & 1.163 & 743.5 & 552792.3 & 411001038 & $3.06 \mathrm{E}+11$ & 864.6905 & 642897.4 \\
\hline 27 & 1.086 & 748.28 & 559923 & 418979151 & $3.14 \mathrm{E}+11$ & 812.6321 & 608076.3 \\
\hline 28 & 0.587 & 761.92 & 580522.1 & 442311388 & $3.37 \mathrm{E}+11$ & 447.247 & 340766.5 \\
\hline 29 & 1.093 & 773.52 & 598333.2 & 462822689 & $3.58 \mathrm{E}+11$ & 845.4574 & 653978.2 \\
\hline 30 & 1.005 & 788.28 & 621385.4 & 489825650 & $3.86 \mathrm{E}+11$ & 792.2214 & 624492.3 \\
\hline Total & 31.7973 & 20371.95 & 13928965 & $9.59 \mathrm{E}+09$ & $6.64 \mathrm{E}+12$ & 21578.98 & 14742733 \\
\hline
\end{tabular}

The technology actually determines the electrical impedance of body tissues, which provides an estimate of total body water (TBW). Using values of TBW derived from BIA, one can then estimate fat-free mass (FFM) and body fat mass (FM). In addition to its use in estimating FM, BIA is beginning to be used in the estimation of body cell mass (BCM), TBW and bone mineral count (BMC) in a variety of clinical conditions as shown in figures 1 and 2.

BIA measures the opposition of body tissues to the flow of a small (less than $1 \mathrm{~mA}$ ) alternating current. Impedance is a function of two components (vectors): the resistance of the tissues themselves, and the additional opposition (reactance) due to the capacitance of membranes, tissue interfaces, and non-ionic tissues. The measured impedance is approximately equivalent to that of muscle tissue. Impedance is a function of frequency of the current used (typically 50 $\mathrm{kHz}$, when a single frequency is used). Applications of BIA increasingly use multi-frequency measurements, or a frequency spectrum to evaluate differences in body composition caused by clinical and nutritional status. In actual use, however, BIA calculations of an individual's body fat may vary by as much as $10 \%$ of body weight because of differences in machines and methodologies used as shown in figure 3 (Patil et al 2012). 


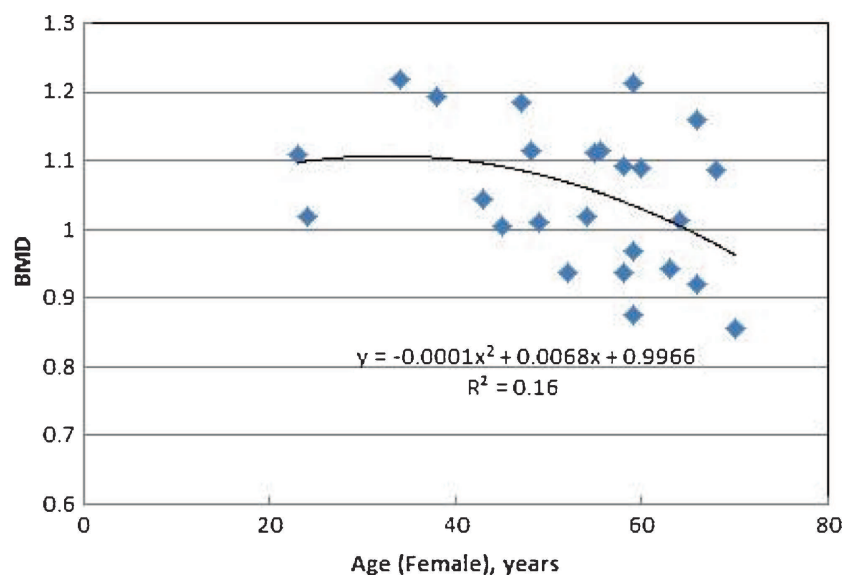

Graph 6. BMD versus age for female patients.

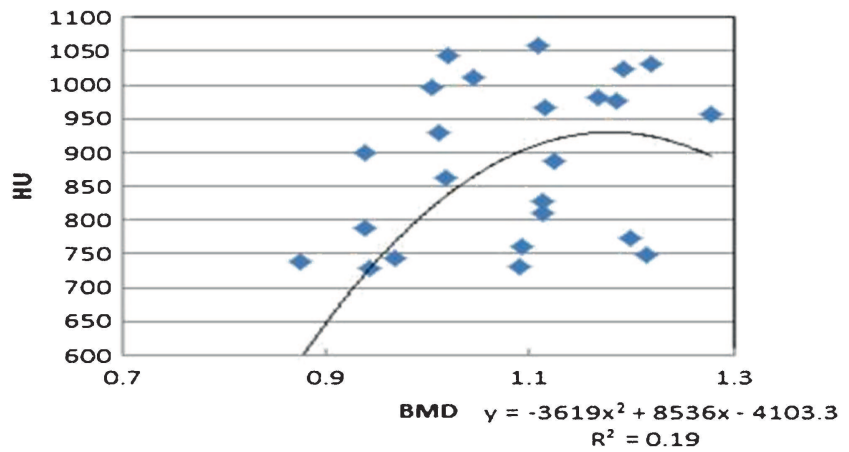

Graph 7. HU versus BMD for 25 patients.

\section{Results and discussions}

In general the methodology and approach for assessing the value of BMD and HU for various patients are studied and compared. The value of BMD is calculated and error analysis for various methods is carried out by using the various methods to assess the most accurate method. The value of T-score,Z-score,BMC,BMD is calculated by using CT scan data and material properties are evaluated by using Mimics software for various patients. This data helps in analysing the value of BMD accurately for various patients.

The different values of BMD, T-score,Z-score,BMC,HU are calculated by using regression analysis and JMPsoftware. The BIA and DEXA are found to be more accurate compared CT

Table 6. The average value of various bone strengths are found as below.

\begin{tabular}{lll}
\hline & Cortical bone $\left(\mathrm{N} / \mathrm{mm}^{2}\right)$ & Cancellous bone $\left(\mathrm{N} / \mathrm{mm}^{2}\right)$ \\
\hline Average tensile strength & 178.65 & 4.4 \\
Average compression & 138.40 & 5.0 \\
strength & 67.30 & 3.0 \\
Modulus of rigidity & 6 \\
\hline
\end{tabular}


scan analysis. The designed experimental set up is used for finding the tensile and compression strengths for proximal femur (as shown in Table 6). Modified correlation between BMD and $\mathrm{HU}$ are validated with the help of experimental results. The analysis is carried out for various age groups (male and female). The exact correlations between BMD and HU for various patients are established. This will help in finding the value of BMD more accurately.

\section{Modified Correlation for cancellous bone is:}

$\mathrm{BMD}=\left\{(-1.39119) * 106^{*}(\mathrm{HU}) 2\right\}+\left\{2.59044^{*} 103^{*}(\mathrm{HU})\right\}-0.10278$

Modified Correlation for cortical bone is:

$\mathrm{BMD}=\left\{(-2.1987)^{*} 10-6^{*}(\mathrm{HU}) 2\right\}+\left\{2.8489^{*} 10-3^{*}(\mathrm{HU})\right\}+0.14613$

\section{Conclusions}

The correlation between BMD and HU is calculated for cortical and cancellous bones and the correlation is validated with the experimental set up for finding the bone strength. In both the bone types, R2 values are more than $90 \%$ giving good correlation. For young adult (age group 43-49) the average value of BMD for male patients is 1.2235 while for female patients it is 1.0724. For adult (age group 52-60), the average value of BMD is 1.1624 while for female patients it is 0.9406. For age group (age match group 60-72), the average value of BMD is 1.1075 while for female patients it is 1.0158. BMD was measured by using BIA method and DEXA. BIA measurements were found more accurate. For males as well as females, as the age goes on increasing, the value of BMD goes on decreasing. Though for, both males and females, the value of BMD appears decreasing considerably after the age of 40, the rate of decrease is found more in case of women patients. Four point hydraulic experimental setup was developed for bone strength evaluation and validation of correlations between HU and BMD. For cancellous bone the percentage error was found between 0.20 to 0.5 and for cortical bones the percentage error was found between 0.3 to 0.32 . Additional mechanical experiments are warranted to make comparisons between the structure-property relationships in bone.

\section{References}

Cesar Libanati, Klaus Engelke and Huei Wang 2009 Quantitative computed tomography (QCT) of the forearm using general purpose spiral whole-body CT scanners: Accuracy, precision and comparison with dual-energy X-ray absorptiometry (DXA). Synarc Inc., San Francisco, USA, and Hamburg, Germany, Institute of Medical Physics, University of Erlangen, Germany, Amgen Inc., Thousand Oaks, CA, USA, University of California, San Francisco, USA

Cristofolini L, Cappello A, Mc Namara B P and Viceconti M 2006 A minimal parametric model of the femur to describe axial elastic strain in response to loads. Med. Eng. Phys. 18(6): 502-514; 1996, 90-98

Damien Subit, Eduardo del Pozo de Dios, Juan Velazquez- Ameijide, Carlos Arregui Dalmasesa and Jeff Crandall 2013 Tensile material properties of human rib cortical bone under quasi-static and dynamic failure loading and influence of the bone microstructure on failure characteristics. Phys. Biophys. pp 1-22

Hanumantharaju H G and Shivanand H K 2010 Strength analysis \& comparison of SS316L, Ti-6AI-4V \& Ti-35Nb-7Zr-5Ta used as orthopaedic implant materials by FEA. In: 2nd international conference on chemical, biological and environmental engineering (ICBEE 2010)

Lengsfeld M, Kaminsky J, Merz B and Franke R P 1996 Sensitivity of femoral strain pattern analyses to resultant and muscle forces at the hip joint. J. Med. Eng. Phys. 18(1): 70-78 
Patil B R, Patkar D P, Mandlik S A, Kuswarkar M M and Jindal G D 2012 Estimation of bone mineral content from bioelectrical impedance analysis in Indian adults aged 23-81 years: A comparison with dual energy X-ray absorptiometry. Int. J. Biomed. Eng. Technol. 8(1)

Raymond E Cole, DO, CCD 2008 Improving clinical decisions for women at risk of osteoporosis: Dual femur bone mineral density testing, vol.108.

Rho J Y, Hobatho M C and Ashman R B 1995 Relations of mechanical properties to density \& CT numbers in human bones. Med. Eng. Phys. 17(5): 347-355

Rodríguez Lelis J M, Marciano Vargas Trevino, Navarro Torres J, Arturo Abundez P, Sergio Reyes Galindo and Dagoberto Vela Arvizo 2007 A qualitative stress analysis of a cross section of the trabecular bone tissue of the femoral head by photoelasticity. Revista Mexicana De Ingeniería Biomédica Xxviii(2): 105-109

Yuehuei H An and Robert A Draughn 2000 Mechanical testing of bone and the bone-implant interface. CRC Press, Washington, PP. 3-219 